\title{
Characteristics of a decellularized human ovarian tissue created by combined protocols and its interaction with human endometrial mesenchymal cells
}

\author{
Maryam Nezhad Sistani ${ }^{1} \cdot$ Saeed $Z a v a r e h^{2} \cdot$ Mojtaba Rezazadeh Valujerdi $^{1} \cdot$ Mojdeh Salehnia $^{1}$ (D)
}

Received: 28 May 2021 / Accepted: 30 August 2021 / Published online: 5 September 2021

(c) Islamic Azad University 2021

\begin{abstract}
The present study makes assessments by analyzing the efficacy of combined decellularization protocol for human ovarian fragments. Tissues were decellularized by freeze-thaw cycles, and treated with Triton X-100 and four concentrations $(0.1$, $0.5,1$ and $1.5 \%$ ) of sodium dodecyl sulfate (SDS) at two exposure times. The morphology and DNA content of decellularized tissues were analyzed, and the group with better morphology and lower DNA content was selected for further assessments. The Acridine orange, Masson's trichrome, Alcian blue, and Periodic Acid-Schiff staining were used for extracellular matrix (ECM) evaluation. The amount of collagen types I and IV, glycosaminoglycans (GAGs), and elastin was quantified by Raman spectroscopy. The fine structure of the scaffold by scanning electron microscopy was studied. The endometrial mesenchymal cells were seeded onto decellularized scaffold by centrifugal method and cultured for 7 days. After $72 \mathrm{~h}$ the treated group with $0.5 \%$ SDS showed well-preserved ECM morphology with the minimum level of DNA $(2.23 \% \pm 0.08)$. Raman spectroscopy analysis confirmed that, the amount of ECM components was not significantly decreased in the decellularized group $(P<0.001)$ in comparison with native control. The electron micrographs demonstrated that the porosity and structure of ECM fibers in the decellularized group was similar to native ovary. The endometrial mesenchymal cells were attached and penetrated into the decellularized scaffold. In conclusion this combined protocol was an effective method to decellularize human ovarian tissue with high preservation of ECM contents, and human endometrial mesenchymal cells which successfully interacted with this created scaffold.
\end{abstract}

Keywords Decellularization · Human ovarian tissue $\cdot$ Human endometrial mesenchymal cells $\cdot$ Raman spectroscopy · Sodium dodecyl sulfate

Mojdeh Salehnia

salehnim@modares.ac.ir

Maryam Nezhad Sistani

m.nezhadsistani@modares.ac.ir

Saeed Zavareh

zavareh.s@du.ac.ir

Mojtaba Rezazadeh Valujerdi

mr_valojerdi@modares.ac.ir

1 Anatomy Department, Faculty of Medical Sciences, Tarbiat Modares University, P.O. BOX: 14115-111, Tehran, Iran

2 School of Biology, Damghan University, Damghan, Iran

\section{Introduction}

The decellularized ovarian tissue (DOT), as a natural bioscaffold, provides several types of molecules, including collagens, glycosaminoglycans (GAGs), and glycoproteins, which involve in folliculogenesis and normal functions of ovarian tissue(Gandolfi et al. 2019; Gargus et al. 2020).

Different protocols have been applied to decellularize mammalian ovaries using physical method, chemical and enzymatic treatment (Laronda et al. 2015; Liu et al. 2017). The initial research for decellularization of the ovary is related to Laronda et al. (2015) who applied sodium dodecyl sulfate (SDS) for removal of cellular materials of human and bovine ovarian tissues. The improvement of decellularization protocol of ovarian tissue by several investigators has produced some controversial results related to properties, and the functionality of these constructed scaffolds 
(Hassanpour et al. 2018; Eivazkhani et al. 2019; Pors et al. 2019; Pennarossa et al. 2020; Nikniaz et al. 2021).

Liu et al. (2017) have developed a combined protocol for porcine ovary by application of freeze-thaw cycles, and treatment with $1 \%$ Triton X-100, SDS, and deoxyribonuclease I (DNase I). Their result demonstrated that this DOT has no cytotoxic effect and it successfully supported the rat granulos a cells penetration ex vivo.

Alshaikh et al. (2019) compared three detergent solutions for decellularization of mouse ovaries, and they concluded that SDS and sodium deoxycholate (SDC) were more effective in removing cellular DNA and components, but, TritonX100 combined with the ionic solution of dimethyl sulphoxide was not effective for this purpose. It may seem that further studies are needed to establish an efficient protocol for the decellularization of ovarian tissue.

Moreover, recellularization of DOT could be done by various cell types and follicles (Liu et al. 2017; Eivazkhani et al. 2019; Pors et al. 2019; Pennarossa et al. 2020).

It is reported by Hassanpour et al. (2018) that the formation of follicle-like structures within the human DOT occurs by seeding rat primary ovarian cells.

In a small number of studies, the DOT was recellularized by mesenchymal cells derived from different sources and, the interaction between these cells and scaffold could control cell behavior (Rajabi et al. 2018; Mirzaeianet al. 2020Na et al. 2020).

Based on the effect of decellularization method on recellularization ability and functionality of the scaffold; the main objective of the present study was to optimize the decellularization method for human ovarian fragments by evaluating different concentrations of SDS without any enzymatic treatment. In addition to routine tests for the first time the Raman spectroscopy was applied for scaffold ECM analysis. In addition, the attachment and penetration of human endometrial mesenchymal cells (hEMCs) on this constructed scaffold was evaluated.

\section{Materials and methods}

All materials and reagents were purchased from Sigma Aldrich (London, UK), except those noted otherwise.

\section{Human ovarian tissue collection}

Human ovaries were achieved from 18- to 25-year-old individuals ( $n=5$ patients) who had undergone transsexual surgery according to the ethical guidelines of Tarbiat Modares University, Tehran, Iran (IR.MODARES.REC.1398.006). The cortical tissues were cut into several segments $(3 \times 1 \times 1$ $\left.\mathrm{mm}^{3}\right)$ and randomly some of them $(n=18$ tissue fragments from 5 ovaries) were used as the native control group, and the others were frozen at $-80{ }^{\circ} \mathrm{C}$ for subsequent decellularization process $(n=72$ tissue fragments in total from 5 ovaries for the first and second steps of decellularization procedure).

\section{Ovarian decellularization protocol}

The human ovarian decellularization was performed based on the Liu et al. (2017) method with some modifications in 8 subgroups. Briefly, ovarian cortical slices ( $n=48$ fragments from 5 patients) were undergone three freezing/thawing cycles with $60 \mathrm{~min}$ intervals. After that, the samples were immersed in $1 \%$ Triton $\mathrm{X}-100$ for $15 \mathrm{~h}$ at room temperature on a rotator at $50 \mathrm{rpm}$. Subsequently, the tissue slices were randomly put in SDS-based solutions at concentrations of $0.1,0.5,1$ and $1.5 \%$ for 48 and $72 \mathrm{~h}$ as 8 subgroups $(n=6$ fragments in each experimental subgroup) at room temperature on a rotator at $50 \mathrm{rpm}$. The SDS solutions were changed at every $24 \mathrm{~h}$ during these processes. Finally, the samples were washed in buffer phosphate saline (PBS) to eliminate the residual detergents and cellular debris, and these solutions changed every $12 \mathrm{~h}$ up to $48 \mathrm{~h}$.

\section{Assessment of DNA content}

After the decellularization procedure, DNA content of samples was extracted using Trizol ${ }^{\circledR}$ Kit (Invitrogen, UK) according to the manufacturer's protocol ( $n=3$ decellularized fragments in each subgroup). This was measured using a spectrophotometer (Eppendorf, Germany) at $260 \mathrm{~nm}$ of optical density and reported as $\mathrm{ng} / \mathrm{mg} / \mathrm{wet}$ weight of tissue. The non-decellularized tissue was considered as native control ( $n=3$ non-treated fragments). The percentage of remaining DNA in all decellularized samples was determined by calculating the ratio of $\mathrm{ng} / \mathrm{mL}$ DNA/mg wet tissue between the native and decellularized tissues.

\section{Histological evaluation}

For histological assessment, the native control and other decellularized subgroupstissue samples ( $n=3$ for each subgroup) were subjected to routine hematoxyline and eosin (H\&E) stainingto evaluate their morphology.

At this stage, according to the collected data obtained from the morphology and DNA content of all studied decellularized tissues, the subgroup that was treated with $0.5 \%$ SDS for $72 \mathrm{~h}$ was selected for subsequent studies. For additional assessments several fragments of ovarian tissue $(n=24)$ were again decellularized as described earlier by doing three freezing/thawing cycles and treating with $1 \%$ Triton X-100 for $15 \mathrm{~h}$ and $0.5 \%$ SDS for $72 \mathrm{~h}$, respectively. 


\section{Acridine orange staining}

The cell removal in selected DOT $(n=3)$ was confirmed using Acridine orange staining. Briefly, after tissue processing and sectioning, another set of tissue sections were prepared and were stained with Acridine orange and observed under a fluorescence microscope (Olympus, BX51, Tokyo, Japan).

\section{Scanning electron microscopy (SEM)}

The tissues ( $n=3$ in each group) were fixed in $2.5 \%$ glutaraldehyde in PBS for $4 \mathrm{~h}$ and dehydrated in ethanol, then; chemical drying was done using hexamethyldisilazane (Merck, Germany) in several steps. Subsequently, the prepared samples were coated with a gold-palladium layer by a sputter coater (Quorum Technologies, UK) and imaged using Phillips 505 microscope (XL29, 25 kV, Kassel, Germany).

\section{Human endometrial tissue collection and culture}

The human endometrial tissue fragments were obtained from women aged 35-45 years $(n=4)$, who had been subjected to hysterectomy according to the ethical guidelines of Tarbiat Modares University, Tehran, Iran (IR.MODARES. REC.1398.006). The patients were on a non-pathological condition and had not additional exogenous hormone treatment at least for 3 months before the operation.

The endometrial stromal cells were prepared according to Fayazi et al. (2015) method. The cultured cells at the fourth passage were assessed by flow cytometry analysis to evaluate mesenchymal (CD90) and non-mesenchymal markers (CD31 and CD34). These mesenchymal cells were applied for the 3-(4,5-dimethylthiazol-2-yl)-2,5-diphenyl-2H-tetrazolium bromide(MTT) assay and cell seeding on the decellularized scaffold.

\section{Cytotoxicity test}

To evaluate the cytotoxicity of selected DOT, MTT test was applied. Before the MTT test, the decellularized scaffold was sterilized by immersing in $70 \%$ ethanol for $30 \mathrm{~min}$, followed by rising three times in PBS containing $100 \mathrm{IU}$ penicillin and $75 \mu \mathrm{g} / \mathrm{mL}$ streptomycin. After that, the scaffolds were exposed to UV light for $20 \mathrm{~min}$. The prepared hEMCs with a density of $1 \times 10^{4}$ cells were co-cultured with DOT in $200 \mu \mathrm{L}$ DMEM-F12 medium supplemented with $10 \%$ fetal bovine serum (FBS, Gibco, UK), 100 IU/ $\mathrm{mL}$ penicillin and, $75 \mu \mathrm{g} / \mathrm{mL}$ streptomycin and incubated at $37^{\circ}$ Cunder $5 \% \mathrm{CO}_{2}$ condition. After $48 \mathrm{~h}$, the scaffolds and medium were removed and, the remaining cells within each well were subjected to $100 \mu \mathrm{L}$ of MTT solution $(1 \mathrm{mg} / \mathrm{mL}$ of
MTT in PBS) and incubated for $4 \mathrm{~h}$. Next, MTT solution was replaced with dimethyl sulphoxide solution in a dark condition for 20 min and, immediately, their optical density was registered at $570 \mathrm{~nm}$ using a microplate reader (Biochrom, Germany). The same culture condition without exposure of cells to DOT was analyzed as a control group. This experiment was repeated three times.

\section{Quantitative study of ECM components}

After fixation of native and DOT samples $(n=3$ in each group) in $10 \%$ formalin and dehydration in increasing concentrations of ethanol, clearing in xylene, and embedding in paraffin wax, they were sectioned at $5 \mu \mathrm{m}$ thickness. Three additional sets of tissue slides were collected and stained separately using Masson' trichrome, Alcian blue ( $\mathrm{pH} 2.5)$, and periodic acid Schiff (PAS) staining to evaluate ECM components, including collagen, GAGs, and carbohydrates, respectively. Images at $40 \mathrm{X}$ magnification ( $n=9$ tissue sections in each sample) were captured and analyzed by the Digimizer software (MedCalc Software Ltd Ostend, Belgium) to quantify ECM component.

\section{Immunohistochemistry for ECM components}

The immunohistochemistry for collagen types I and IV and fibronectin were done according to the previous study (Laronda et al. 2015; Hassanpour et al. 2018) with some modifications. Briefly, three sets of tissue sections were prepared and deparaffinized, rehydrated, and washed in Tris-buffered saline (TBS; pH 8.4). Then, the tissues were immersed in citrate buffer (pH6.0) and Tween 20 as antigen retrieval agent to unmask the antigenic epitope in $95-100{ }^{\circ} \mathrm{C}$ for 10 min. Blocking of the non-specific binding sites was performed by donkey serum (1:100 dilutions in PBS) for $30 \mathrm{~min}$. These sections were incubated with primary antibodies (rabbit anti-human IgG) separately including: anticollagen type I (1:100 dilutions, Elabscience, China), anticollagen type IV (1:100 dilutions, Elabscience, China), anti-fibronectin (1:100 dilutions, Elabscience, China) at $4{ }^{\circ} \mathrm{C}$ for overnight. Secondary antibodies (goat anti-rabbit FITC conjugated antibody; 1:100 dilutions in PBS, Elabscience, China) were added after raising the tissue sections in TBS and incubated at room temperature for $1 \mathrm{~h}$. Finally, propidium iodide staining was done for nuclear staining.

\section{Raman confocal microspectroscopy}

To quantify collagen type I and IV, elastin, and GAGs in both studied groups ( $n=3$ in each group), Raman confocal spectroscopy (Horiba, XploRA Plus, Japan) was applied using the excitation laser wavelength at $785 \mathrm{~nm}$. The wavenumber range of $450-1600 \mathrm{~cm}^{-1}$ were considered 
to analyze the Raman spectra (Janko et al. 2010; Gullekson et al. 2011; Lim et al. 2011; Nguyen et al. 2012; Borel et al. 2015; Bergholt et al. 2016, 2019).Besides, an acquisition time of $4 \mathrm{~s}$ and one accumulation were obtained for each sample. The intensity of wavenumbers was considered in $820-939 \mathrm{~cm}^{-1}$ for collagen type I, $1000 \mathrm{~cm}^{-1}$ for collagen type IV, $1250-1340 \mathrm{~cm}^{-1}$ for elastin and $1375-1410 \mathrm{~cm}^{-1}$ for GAG according to the previous studies (Janko et al. 2010; Gullekson et al. 2011; Lim et al. 2011; Nguyen et al. 2012; Borel et al. 2015; Bergholt et al. 2016, 2019).

\section{Biodegradation assay}

Biodegradation was performed as described previously (Simsa et al. 2018). Decellularized ovarian fragments were dried by lyophilization and weighed $(n=6)$. These fragments were divided into two groups: treated with collagenase type I (experimental) and non-treated (control) groups ( $n=3$ for each group).

The samples in control groups were placed only in PBS, while the samples in the experimental groups were placed in $0.1 \%$ collagenase type I (Invitrogen, UK) at $37^{\circ} \mathrm{C}$. Next, the tissue fragments were removed individually and dried again by lyophilization and reweighed. Subsequently, the masses of the DOT segments in the control and experimental groups were measured at 24 , and $48 \mathrm{~h}$ of incubation. Biodegradation, was calculated with the following equation:

Degradation $(\%)=100 \times\left(W_{0}-W_{t}\right) / W_{t}$

$W_{0}$ represents the initial weight and $W_{t}$ the measured weight of the tissue sample at timepoint $t$ (Kim et al. 2012). The results are presented as mean percent \pm standard deviations.

\section{Recellularization of decellularized scaffolds}

After confirmation of endometrial mesenchymal cells by flow cytometry at the fourth passage, these cells with $5 \times 10^{4} / \mathrm{mL}$ concentration were labeled with DiI fluorescence dye $(2 \mu \mathrm{g} / \mathrm{mL}$ in PBS $)$ and seeded onto DOT $\left(3 \times 1 \times 1 \mathrm{~mm}^{3}\right.$ size; $n=3$ scaffold) by a modified centrifugal method in $4000 \mathrm{rpm}$ rate twice for $6 \mathrm{~min}$ ( $\mathrm{Lv}$ et al. 2016). In the following, these scaffolds were placed in 200 mLDMEM-F12 medium supplemented with $10 \%$ fetal bovine serum (FBS, Gibco, UK), $100 \mathrm{IU} / \mathrm{mL}$ penicillin, and $75 \mu \mathrm{g} / \mathrm{mL}$ streptomycin and incubated in $37{ }^{\circ} \mathrm{C}$ at $5 \% \mathrm{CO}_{2}$ in 96 well plate condition for 7 days, while $2 / 3$ medium changed once every 3 days. At the end of cultivation, the scaffolds were cryosectioned by cryostat (Leica CM 1850, Germany) at $5 \mu \mathrm{m}$ thickness and then visualized under a fluorescent microscope (Olympus, BX51, Tokyo, Japan).

\section{Statistical analyses}

The data were analyzed with SPSS software (version 24; Chicago, IL, USA). The Shapiro-Wilk normality test was carried out and confirmed the normality distribution of the data, and therefore, parametric tests were done. The statistical analysis for DNA content was performed with a oneway analysis of variance (ANOVA) followed by a post hoc Tukey's Honest Significant Difference test. In addition, data of ECM content and MTT assay were analyzed by independent Student's $t$ test. Statistical significance was considered at $P<0.05$. The data are presented as mean \pm SD.

\section{Results}

\section{DNA content analysis}

As illustrated in Fig. 1A, the amount of DNA in all decellularized tissue samples decreased significantly $(<20 \%)$ compared with the native control group $(P<0.05)$. The detected amount of DNA in subgroups, treated with 0.1, $0.5,1,1.5 \%$ SDS for $48 \mathrm{~h}$, were $16.4 \%, 12.18 \%, 8.25 \%$ and $7.4 \%$, respectively, and the same amounts for the previous subgroups treated for $72 \mathrm{~h}$, were $10.47 \%, 2.25 \%, 3.47 \%$ and $3.08 \%$, respectively. Among these studied subgroups, the lowest percentage of DNA content was significantly seen in the subgroup that was treated with $0.5 \%$ SDS for $72 \mathrm{~h}$.

\section{Morphological observation}

The microscopic observation of all experimental groups using H\&E staining revealed proper removal of the cell nucleus and well preserved tissue structures such as vasculatures and fibrillar components similar to the native control tissue (Fig. 1B-J).

\section{Acridine orange staining}

The micrographs of native control and DOT stained with Acridine orange are presented in Fig. 2A, B, respectively. These micrographs may illustrate any evidence of the nucleus in the selected scaffold, while the green staining showed the presence of the nuclei within the native control group.

\section{SEM observation}

The representative SEM micrographs related to the control and DOT are presented in Fig. 2C, D. As these figures revealed, the ultrastructure of decellularized tissue, including the integrity of stroma and the collagen fibers and their orientation, were detected as well as the native tissue. 

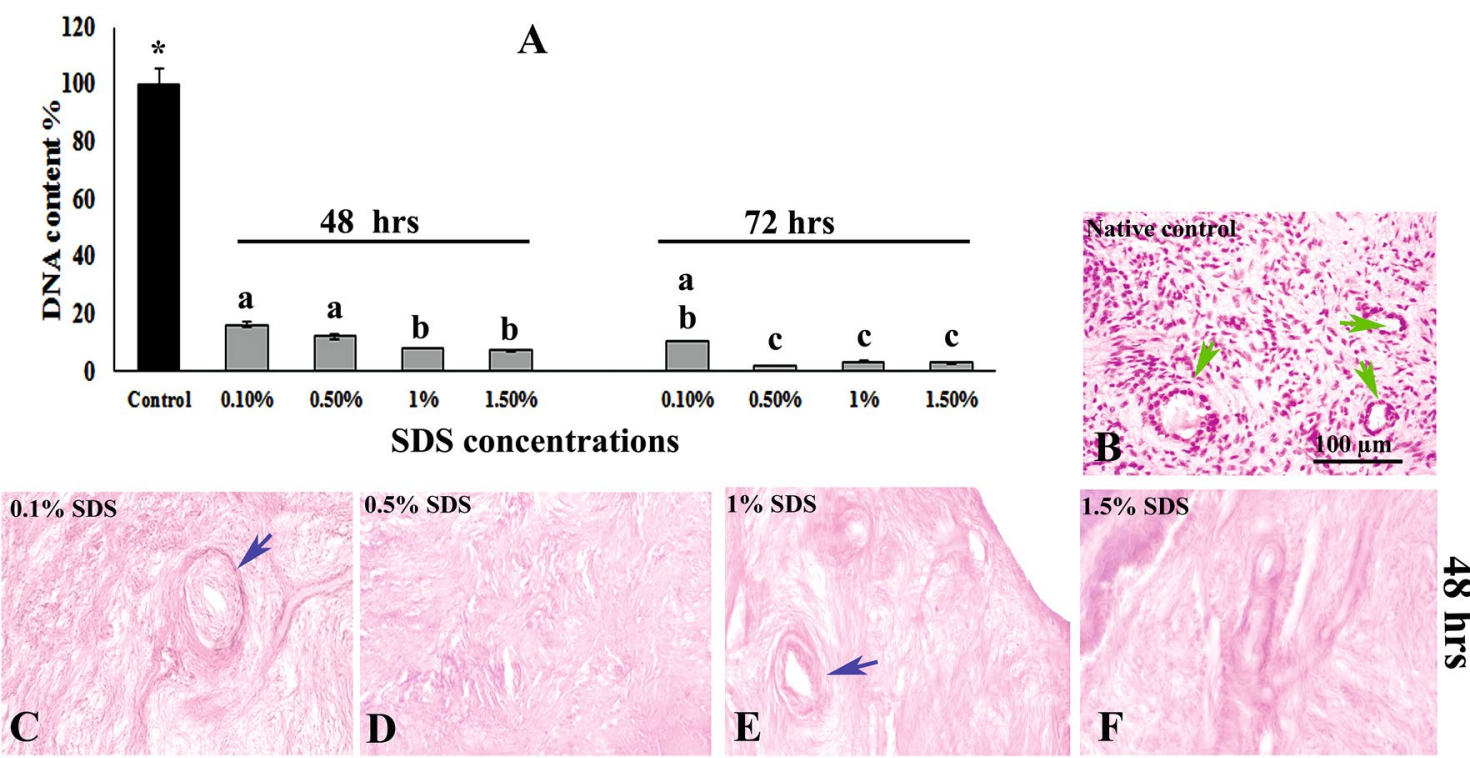

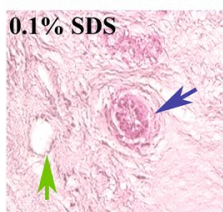

G

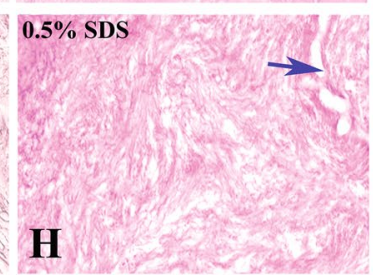

$1 \%$ SDS

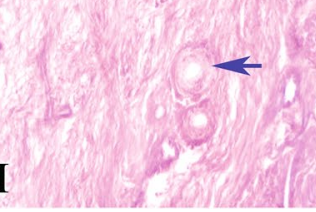

$1.5 \%$ SDS

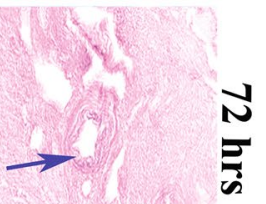

J
Fig. 1 Comparison of the mean percentages of DNA content in native control and all decellularized tissues (A). *Showed significant differences between the native control and other studied subgroups $(P$ $<0.05)$. In addition, the same letters show no significant difference among the studied subgroups. Hematoxylin and eosin staining of

Some different size pores were observed in the cortical region of ovarian tissue that could be related to follicular pockets or blood vessels. The arrowhead in Fig. 2C showed the presence of flattening stromal cells in native tissue and their absence in decellularized scaffold.

\section{MTT assay}

The data relating to MTT analysis of DOT in the presence of hEMCs are presented in Fig. 2E. As it is shown, during $48 \mathrm{~h}$ in vitro culture the recorded optical density values are $0.96 \pm 0.1$ and $0.95 \pm 0.1$ in control and selected decellularized groups, respectively. There seems no significant difference in cell viability and density between these two groups.

\section{Extracellular matrix composition analysis}

Alcian blue staining revealed that the pattern of GAGs distribution in selected DOT was similar to the native group (Fig. 3A, B), and the mean percentages of area fraction of this component were $35.22 \% \pm 8.94$ and $38.60 \% \pm 11.84$ in selected decellularized and native tissues, respectively experimental and control tissues. Native ovarian tissue (B), decellularized human ovarian tissue treated with different concentrations of SDS for $48(\mathbf{C}-\mathbf{F})$ and $72 \mathrm{~h}(\mathbf{G}-\mathbf{J})$. Dark blue arrows indicate the blood vessel structure, and green arrows show the follicular pocket in decellularized tissue or follicle in native control

(Fig. 3C). In addition, the neutral carbohydrates component within the stroma and around of blood vessels was shown by PAS staining in both studied groups in Fig. 3D, E. The qualitative analysis of these components showed that the average percentages of area fraction of carbohydrates was $43.1 \% \pm 9.04$ in DOT and was $50.6 \% \pm 6.2$ in native tissue (Fig. 3F). Morphology of the decellularized and native tissues using Masson' trichrome staining is demonstrated in Fig. 3G, H. According to these figures, the collagen fibers were distributed in the same manner in both groups. The quantitative analysis showed the amount of collagen fibers in the previous groups were $47.76 \% \pm 3.22$ and $52.03 \% \pm 9.34$ (\% of area fraction) (Fig. 3I).

There appears no significant difference in the level of GAGs, carbohydrate, and collagen between the two studied groups $(P>0.05)$.

\section{Immunohistochemistry}

Immunofluorescence images revealed that the distribution of collagen type I as the majority ECM component in the selected DOT was similar to that of native tissue (Fig. 4A, 

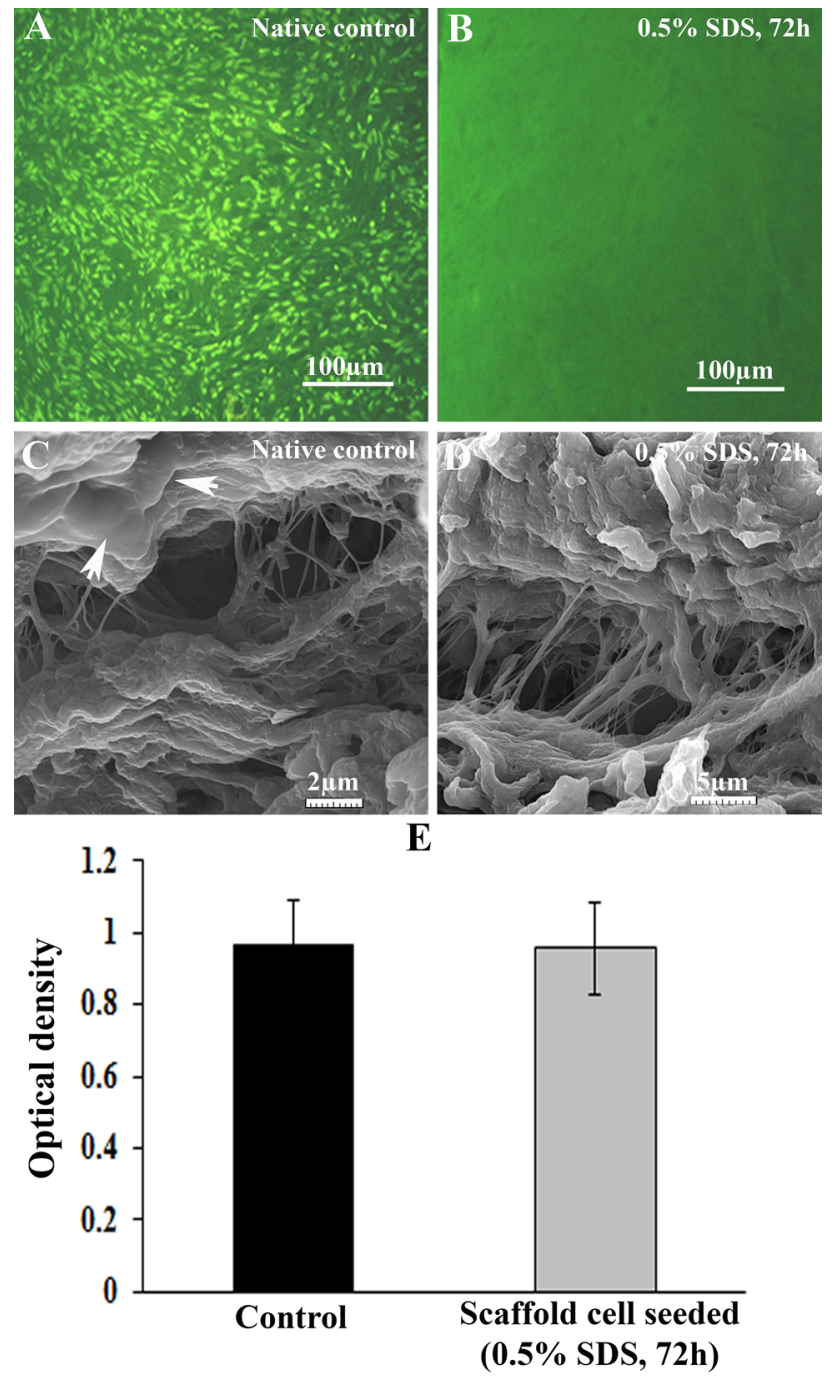

Fig. 2 Acridine orange staining in studied groups. The representative figures of native and selected decellularized ovarian tissue are demonstrated in parts $\mathbf{A}$ and $\mathbf{B}$, respectively. The nucleus was stained green, and there was not any stained nucleus in the decellularized group. Representative scanning electron micrographs in native control and decellularized ovarian tissue are demonstrated in parts $\mathbf{C}$ and D, respectively. White arrows indicate the cells in native control tissue. MTT assay results of cultured human endometrial mesenchymal cells with decellularized scaffold $48 \mathrm{~h}$ after cultivation were shown in part $\mathbf{E}$. There was no significant decrease in the optical density (wavelength) of cells during the culture period

\section{Raman confocal analysis}

The peak intensity of each ECM component, obtained by Raman confocal spectroscopy, is presented in Fig. 5 . There seems a long peak between 820 and $939 \mathrm{~cm}^{-1}$ wavenumbers in native and DOT groups that, is related to collagen type I and their mean percentage intensity are $87.20 \% \pm 4.21$ and $87.28 \% \pm 3.20$, respectively. Corresponding to collagen type IV in previous groups, the peak intensities (mean percentage) were $43.08 \% \pm 6.18$ and $36.70 \% \pm 6.64$ (in $1000 \mathrm{~cm}^{-1}$ ), respectively. In addition, the average percentages of peak intensity, related to GAGs are $12.84 \% \pm 8.55$ and $8.55 \% \pm 4.67\left(1375-1396 \mathrm{~cm}^{-1}\right)$, and the same for elastin $\left(1250-1340 \mathrm{~cm}^{-1}\right)$ are $17.34 \% \pm 1.88$ and $11.50 \% \pm 3.42$ in native and DOT groups, respectively. As presented in Fig. 5C, there is no statistically difference between the two studied groups $(P>0.05)$.

\section{Decellularized ovarian tissue biodegradable test}

An in vitro biodegradability test with collagenase I was performed to test the DOT and their data are compared in Fig. 6 . The degradation percentages of experimental DOT samples after 24 and $48 \mathrm{~h}$ incubation were $15.75 \pm 6.58$ and $34.90 \pm 5.94$, respectively. These percentages are $4.02 \pm 3.90$ and $6.33 \pm 6.40$ in the control group at 24 and $48 \mathrm{~h}$, respectively. After 24 and $48 \mathrm{~h}$, a significantly loss of tissue weight was observed in the experimental group in comparison with control $(P<0.05)$.

\section{The morphology and phenotypic analysis of cultured endometrial stromal cells}

The morphology of cultured endometrial stromal cells under an inverted microscope at the end of passages 1 and 4 are presented in Fig. 7A, B, respectively. These cells appear as flattened, and spindle-shaped and are more homogenous at the fourth passage.

After the flow cytometry analysis (Fig. 7C-E), these cultured cells showed the typical mesenchymal cell surface phenotype for markers CD90 $(97.66 \% \pm 0.1)$, and they were negative for endothelial cells markers CD31 $(0.86 \% \pm 0.1)$ and hematopoietic markers CD34 $(0.40 \% \pm 0.5)$.

\section{Cell attachment and penetration}

observed clearly around the blood vessels (Fig. 4C, D). In addition, the distribution of fibronectin was detectable throughout the selected scaffold as well as native tissue (Fig. 4E, F).
The representative figures of cryosections of labeled hEMCs with DiI that were seeded on DOT and presented in Fig. 7F, G. As these photographs show, these labeled cells are 

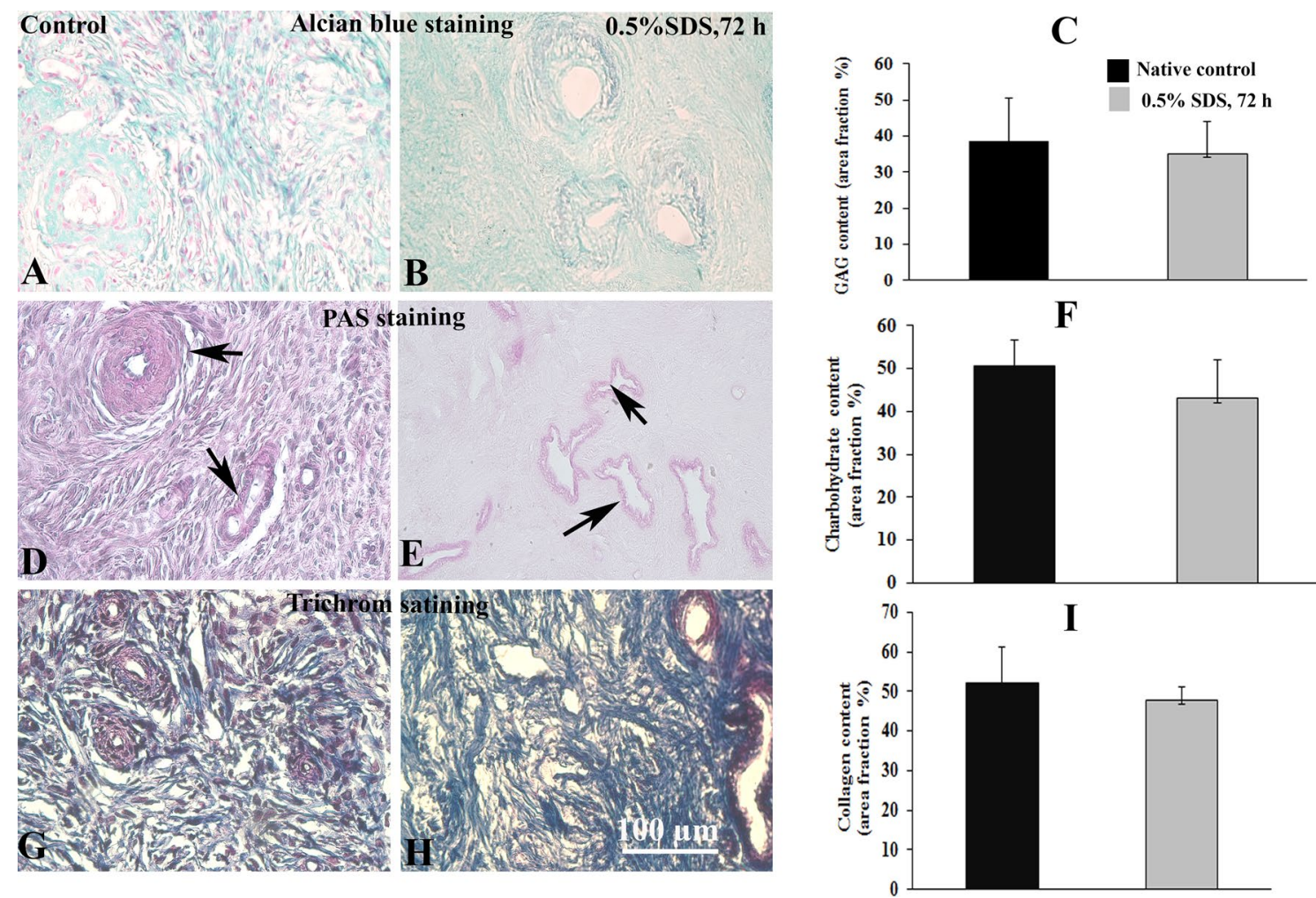

Fig. 3 Light microscopic observations of experimental and control tissues that stained for extracellular matrix components. Representative micrographs of Alcian blue staining of control and selected decellularized tissues $(0.5 \%$ SDS for $72 \mathrm{~h})$ for demonstrating the glycosaminoglycans (GAGs) are presented in parts $\mathbf{A}$ and $\mathbf{B}$, respectively, and the quantitative analysis of GAG content is presented in C. The periodic acid Schiff reaction for carbohydrates components in the decellularized scaffold and native control is shown in $\mathbf{D}$ and $\mathbf{E}$,

evident on the surface as well as at the deeper part of the selected scaffold.

\section{Discussion}

The present study aimed to analyze the efficiency of decellularization of human ovarian tissue by combined physical and chemical protocol using different concentrations of SDS. Our morphological observations, obtained from H\&E and other staining methods, showed the morphology of all experimental subgroups as similar to native control and this structure has been well preserved in the subgroup which had been treated with $0.5 \%$ SDS for $72 \mathrm{~h}$. It is suggested that minimum destruction of ECM elements, especially in the wall of blood vessels, could be essential for the establishment of systems for nutrient and gas exchange, and also for providing a suitable route for cell movement and migration during the recellularization process. respectively. The amount of this reaction has been analyzed and compared between these two groups in part $\mathbf{F}$. The observations of previous groups that stained by Masson's trichrome staining are presented in parts $\mathbf{G}$ and $\mathbf{H}$, respectively. Their collagen content is demonstrated blue, and its amount is compared between these two groups in part $\mathbf{I}$. Black arrow shows the vascular structure in the studied groups. There seems no significant difference between groups regarding the GAGs, carbohydrate, and collagen

In comparison with other research works, we did some modifications in the decellularization protocol, for example; we applied the protocol without any enzymatic treatment. We suggested that additional chemical treatment could affect the biochemical component of ECM; thus the simplified procedure might better preserve the biochemical properties of the scaffold. However, these properties are very important for the subsequent scaffold recellularization. Similarly, Pors et al. (2019), using SDS detergent, showed human ovarian tissue was decellularized by eliminating all cells and leaving their ECM intact.

In contrast to our results, other investigators showed deleterious effects of SDS treatment upon the integrity of ovarian ECM (Eivazkhani et al. 2019; Alshaikh et al. 2019), and its effect is suggested to be more related to its concentration and its exposure time.

Alshaikh et al. (2019) demonstrated that the SDStreated ovarian scaffold contained minimum amounts of cellular DNA but it preserved lesser components of the 
Fig. 4 Immunostaining of ECM components in native tissue (first column) and selected decellularized tissue (second column). Collagen I (A and B), collagen IV (C and D), and fibronectin ( $\mathbf{E}$ and $\mathbf{F}$ ) show in green stain, and red dots represent the cell's nucleus that is stained by propidium iodide (PI). The white arrowheads indicate blood vessel structure
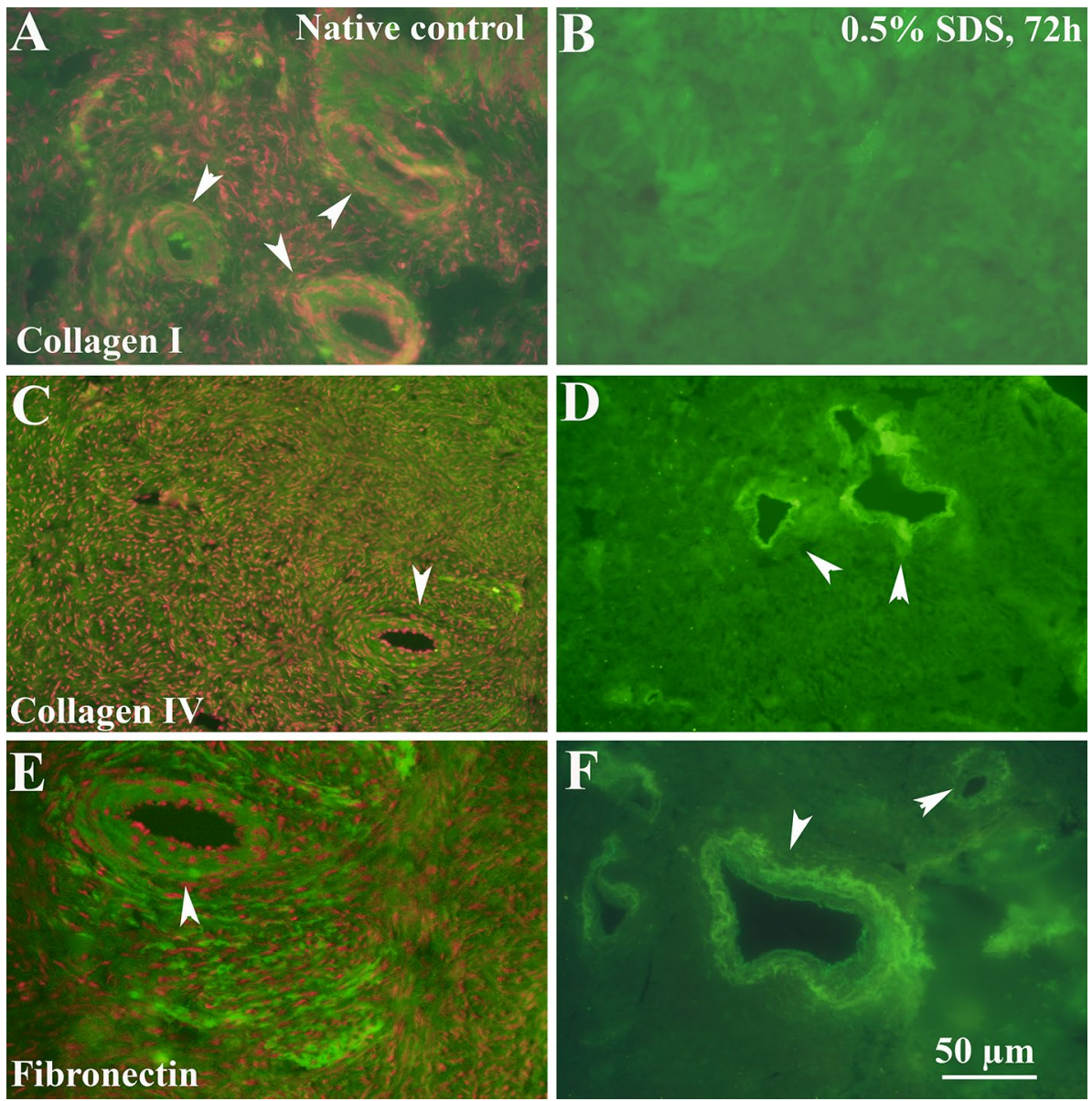

extracellular matrix than the ovaries that were treated with other detergents.

In the present study the effectiveness of our selected protocol $(0.5 \%$ SDS for $72 \mathrm{~h}$ ) without any usage of the enzymatic treatment was confirmed with the lower amount of residual DNA content $(0.2 \%)$ in comparison with other published results (Laronda et al. 2015; Liu et al. 2017; Eivazkhani et al. 2019; Pors et al. 2019; Alshaikh et al. 2019).

Laronda et al. (2015) similar to our applied decellularization procedure of human and bovine ovaries without any enzymatic treatment utilized $0.1 \%$ SDS solution for this purpose and reported $85 \%$ DNA removal from decellularized tissue.

While Liu et al. (2017) demonstrated that after treatment of pig ovarian tissue fragments by freeze/thaw cycles, $1 \%$ Triton X-100, 0.5\% SDS and DNase I, the reduction in DNA content was observed from 701.62-469.28 ng/mg (native ones) to $20.92-4.56 \mathrm{ng} / \mathrm{mg}$ dry weight in decellularized tissue.

Pors et al. (2019) and Eivazkhani et al. (2019) demonstrated that 90 and $95 \%$ DNA elimination in DOT which were treated with $0.1 \%$ and $1 \%$ SDS for $24 \mathrm{~h}$ followed with DNase treatment.
Alshaikh et al. (2019) also reported that in SDC-treated whole mouse ovaries, the DNA content was reduced by about $12 \%$ of its original DNA content in native control.

Recently Niknias et al. (2021) carried out a study to compare decellularization of the human ovarian scaffold by treatment with SDS-Triton-ammonium. In contrast to our finding their analysis showed that a higher amount of DNA content $(24.1 \% \pm 3.7 \%)$ was remaining within the decellularized samples.

Moreover, in comparison of two exposure times of SDS, our data revealed that $72 \mathrm{~h}$ treatment was significantly effective than $48 \mathrm{~h}$ to decellularized tissue. In addition, we have done freezing/thawing cycles at the first step of the decellularization procedure, and it may cause an increase in cell permeability for SDS (Gilpin and Yang 2017; Kawecki et al. 2018).

Because SDS is an anionic detergent, its complete removal from the scaffold is necessary to prevent its cytotoxicity. Our MTT assay results confirmed that the created scaffold had no cytotoxic effect.

Our ultrastructural observation, using SEM with high magnification, revealed the porosity and collagenous fibers architecture in the selected scaffold was the same as 

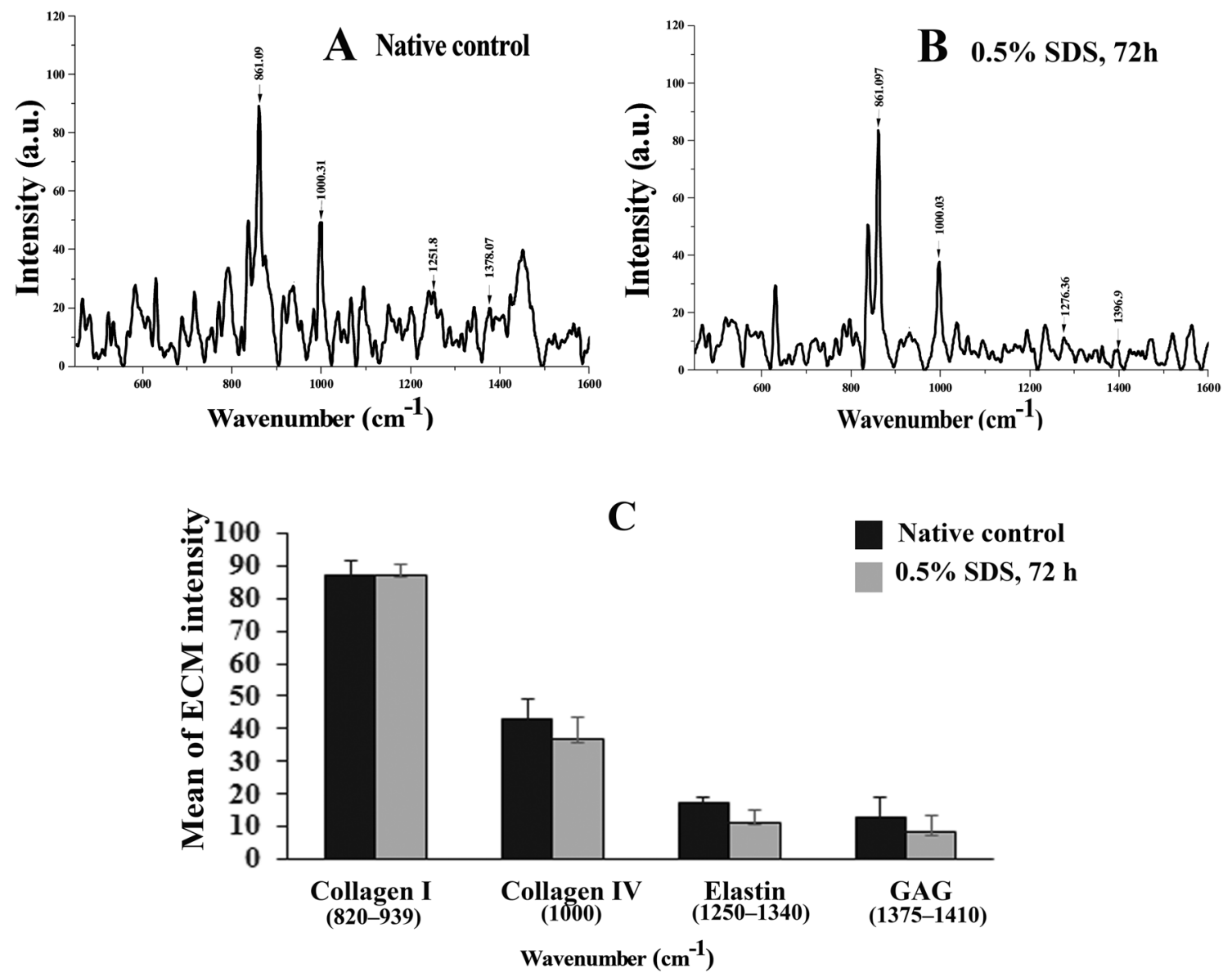

Fig. 5 Raman spectra of extracellular components in studied groups. The band intensity associated with collagen types I, and IV, glycosaminoglycans (GAGs), and elastin are presented in control (A) and selected decellularized scaffold $(\mathbf{B})$. The comparison of quantitative

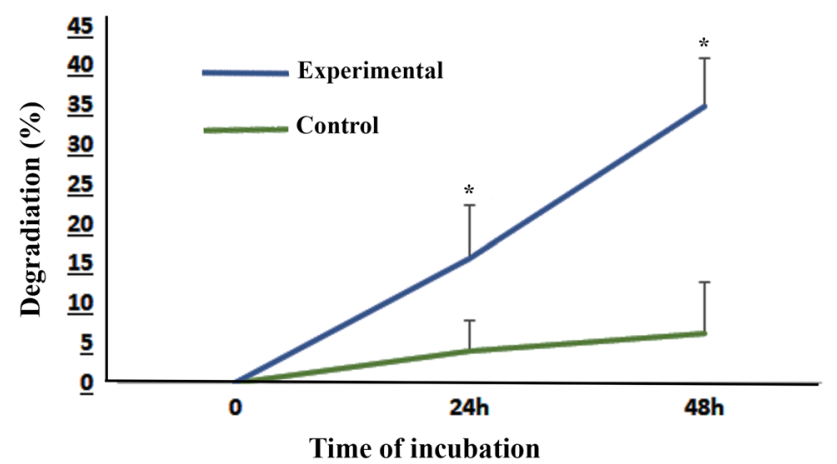

Fig. 6 Assessment of tissue biodegradability. The diagram shows the percentage of degraded tissue weight during $24 \mathrm{~h}$ and $48 \mathrm{~h}$ incubation. Data are shown as means \pm SD. ${ }^{*}$ Shows the significant differences between the experimental (decellularized) samples that treated with $0.1 \%$ collagenase after 24 and $48 \mathrm{~h}$ with non-treated control group $(P<0.05)$ amount of collagen types I and IV, GAGs, and elastin between the two studied groups were presented in part $\mathbf{C}$, and there was no significant difference between them. $(P>0.05)$

native tissue. The presence of this stiffness and porosity is an essential factor for penetration, migration, and expansion of seeded cells.

The ECM molecules may be destroyed or damaged by exposure to decellularization detergent (White et al. 2014, 2017; Porzionato et al. 2018). Ourqualitative and quantitative histological evaluations and Raman confocal spectroscopy analysis revealed that the amount of collagen, GAGs, carbohydrates, and elastin is not significantly changed in comparison with the intact control sample. The Raman spectroscopy technique is a powerful, fast and non-invasive instrument to analyze the biological components in situ. In addition, it is able to report subtle changes in ECM molecular structure according to the chemical bond distribution scheme of its constituent molecules (Movasaghi et al. 2007; Bergholt et al. 2016).

Raman spectroscopic results showed the sharp peaks between wavenumbers $820-939 \mathrm{~cm}^{-1}$ in both studied groups, which can be relevant to $\mathrm{C}-\mathrm{C}$ stretch in proline and hydroxyproline amino acids (Janko et al. 2010; Nguyen 

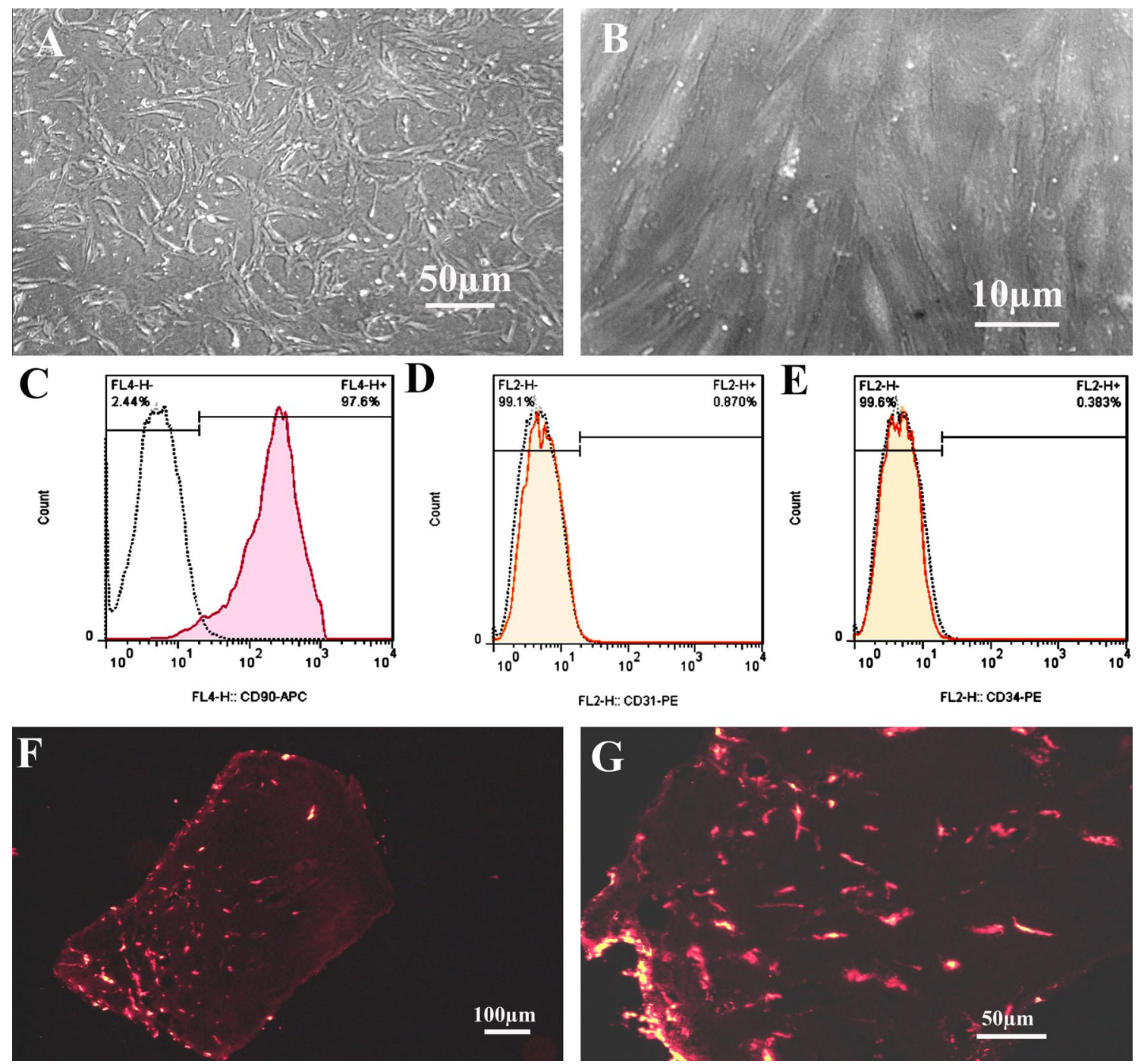

Fig. 7 Inverted microscope micrographs of cultured endometrial stromal cells. Their morphology on the first and fourth passages are presented in parts $\mathbf{A}$ and $\mathbf{B}$, respectively. The flow cytometry analysis of these cultured cells at the fourth passage were shown for mesenchymal cell marker CD90 (C), endothelial cell marker CD31 (D), and

et al. 2012; Borel et al. 2015; Bergholt et al. 2019). In addition, a robust peak in $1000 \mathrm{~cm}^{-1}$ wavenumber which can be associated with phenylalanineamino acid that is related to collagen IV in comparison with collagen type I (Movasaghi et al. 2007; Nguyen et al. 2012; Borel et al. 2015). Collagen and proteoglycans are structural elements or ligands in the extracellular matrix, that are interacted with growth factors, cytokines, cell surface receptors, and other ECM molecules (Pomin et al. 2018). In addition, the immunohistochemistry observations in our study revealed that, the basal lamina remained intact after the decellularization procedure, and these structures provide structural support or signal for cell adhesion, migration, proliferation, and differentiation. hematopoietic cell marker CD34 (E). The representative micrographs of cryosections that obtained from recellularized scaffold by labeled human endometrial mesenchymal cells with DiI fluorescence dye at low and high magnifications are presented in parts $\mathbf{F}$ and $\mathbf{G}$

In other part of the present study our observations showed that DOT was affected by collagenase treatment during biodegradable test. It seems that the ECM of created scaffold was less stable during these incubation times. Moreover, it is suggested that after its transplantation into the host body it could undergo remodeling. However, more additional test could be done in longer time of incubation with enzyme to prove this suggestion.

The present study is the preliminary experiment showed the endometrial mesenchymal cells successfully interacted and attached to the human DOT. This finding could direct us to the usage of these cells for bioengineering ovarian scaffold to support follicular and oocytes development. A similar function of mesenchymal cells via paracrine and autocrine 
signaling pathways previously reported in in vitro experiments or in chemically induced premature ovarian failure models (Xia et al. 2015; Fazeli et al. 2018; Huang et al. 2018; Feng et al. 2019; Lim et al. 2019; Na et al. 2020; Alshaikh et al. 2020).

In addition, this strategy could be an alternative method to improve the fertility potential of cancer patients without any risk for re-transplantation of malignant cells during the process of cryopreserved ovarian tissue grafting. In addition, transplantation of bioengineered ovary by application of the decellularized tissue as a new niche for homing the ovarian cells in combination with mesenchymal stem cells may be developed as a strategy for improving infertility treatment.

\section{Conclusion}

The applied combined protocol that employed three freezing/thawing cycles and treatment with $1 \%$ Triton X-100 for $15 \mathrm{~h}$ and $0.5 \%$ SDS for $72 \mathrm{~h}$ was effective in decellularization of human ovarian tissue with high level of preservation of ECM contents and non-cytotoxicity properties. In addition, human endometrial mesenchymal cells successfully interacted with this created scaffold and attached and penetrated within it. This study was the first steps toward the recellularization of this created scaffold by human endometrial mesenchymal cells.

Acknowledgements This work was supported by Tarbiat Modares University of Medical Sciences as a Ph.D. thesis. Special thanks to Mr. Pour Bayranvand for technical assistance.

Author contributions MNS performed the experiments, analyzed the data, and contributed to writing the draft of the manuscript. MRV involved in protocol development. MS and SZ supervised the study and contributed to writing the manuscript. All authors reviewed and edited the manuscript and approved the final version of the manuscript.

\section{Declarations}

Conflict of interest The authors clarify there is no conflict of interest.

Ethical approval All procedures performed in studies involving human participants were in accordance with the ethical standards of the ethical guidelines of Tarbiat Modares University, Tehran, Iran (IR. MODARES.REC.1398.006) and with the 1964 Helsinki declaration and its later amendments or comparable ethical standards.

Informed consent Informed consent was obtained from all individual participants included in the study.

\section{References}

Alshaikh AB, Padma AM, Dehlin M, Akouri R, Song MJ, Brännström M, Hellström M (2019) Decellularization of the mouse ovary: comparison of different scaffold generation protocols for future ovarian bioengineering. J Ovarian Res 12:1-9. https://doi.org/10.1186/s13048-019-0531-3

Alshaikh AB, Padma AM, Dehlin M, Akouri R, Song MJ, Brännström M, Hellström M (2020) Decellularization and recellularization of the ovary for bioengineering applications; studies in the mouse. Reprod Biol Endocrinol 18:1-10. https://doi.org/ 10.1186/s12958-020-00630-y

Bergholt MS, Serio A, Albro MB (2016) Raman spectroscopy reveals new insights into the zonal organization of native and tissue-engineered articular cartilage. ACS Cent Sci 2:885-895. https://doi.org/10.1021/acscentsci.6b00222

Bergholt MS, Serio A, Albro MB (2019) Raman spectroscopy: guiding light for the extracellular matrix. Front Bioeng Biotechnol 7:303. https://doi.org/10.3389/fbioe.2019.00303

Borel S, Prikryl EA, Vuong NH, Jonkman J, Vanderhyden B, Wilson BC, Murugkar S (2015) Discrimination of normal and malignant mouse ovarian surface epithelial cells in vitro using Raman microspectroscopy. Anal Methods 7:9520-9528. https://doi.org/ 10.1039/C5AY02462E

Eivazkhani F, Abtahi NS, Tavana S, Mirzaeian L, Abedi F, Ebrahimi B, Montazeri L, Valojerdi MR, Fathi R (2019) Evaluating two ovarian decellularization methods in three species. Mater Sci Eng C 102:670-682. https://doi.org/10.1016/j.msec.2019.04. 092

Faulk DM, Carruthers CA, Warner HJ, Kramer CR, Reing JE, Zhang L, D'Amore A, Badylak SF (2014) The effect of detergents on the basement membrane complex of a biologic scaffold material. Acta Biomater 10:183-193. https://doi.org/10.1016/j.actbio.2013.09.006

Fayazi M, Salehnia M, Ziaei S (2015) Differentiation of human CD146-positive endometrial stem cells to adipogenic-, osteogenic-, neural progenitor-, and glial-like cells. Vitro Cell Dev Biol Anim 51(4):408-414. https://doi.org/10.1007/ s11626-014-9842-2

Fazeli Z, Abedindo A, Omrani MD, Ghaderian SMH (2018) Mesenchymal stem cells (MSCs) therapy for recovery of fertility: a systematic review. Stem Cell Rev Rep 14:1-12. https://doi.org/10. 1007/s12015-017-9765-x

Feng P, Li P, Tan J (2019) Human menstrual blood-derived stromal cells promote recovery of premature ovarian insufficiency via regulating the ECM-dependent FAK/AKT signaling. Stem Cell Rev Rep 15:241-255. https://doi.org/10.1007/s12015-018-9867-0

Gandolfi F, Ghiringhelli M, Brevini TA (2019) Bioengineering the ovary to preserve and reestablish female fertility. Anim Reprod 16:45. https://doi.org/10.21451/1984-3143-AR2018-0099

Gargus ES, Rogers HB, McKinnon KE, Edmonds ME, Woodruff TK (2020) Engineered reproductive tissues. Nat Biomed Eng 4:381393. https://doi.org/10.1038/s41551-020-0525-x

Gilpin A, Yang Y (2017) Decellularization strategies for regenerative medicine: from processing techniques to applications. Biomed Res Int. https://doi.org/10.1155/2017/9831534

Gullekson C, Lucas L, Hewitt K, Kreplak L (2011) Surface-sensitive Raman spectroscopy of collagen I fibrils. Biophys J 100(7):18371845. https://doi.org/10.1016/j.bpj.2011.02.026

Hassanpour A, Talaei-Khozani T, Kargar-Abarghouei E, Razban V, Vojdani Z (2018) Decellularized human ovarian scaffold based on a sodium lauryl ester sulfate (SLES)-treated protocol, as a natural three-dimensional scaffold for construction of bioengineered ovaries. Stem Cell Res Ther 9:1-13. https://doi.org/10. 1186/s13287-018-0971-5

Huang B, Lu J, Ding C, Zou Q, Wang W, Li H (2018) Exosomes derived from human adipose mesenchymal stem cells improve ovary function of premature ovarian insufficiency by targeting SMAD. Stem Cell Res Ther 9:1-12. https://doi.org/10.1186/ s13287-018-0953-7 
Janko M, Davydovskaya P, Bauer M, Zink A, Stark RW (2010) Anisotropic Raman scattering in collagen bundles. Opt Lett 35:27652767. https://doi.org/10.1364/OL.35.002765

Kawecki M, Łabuś W, Klama-Baryla A, Kitala D, Kraut M, Glik J, Misiuga M, Nowak M, Bielecki T, Kasperczyk A (2018) A review of decellurization methods caused by an urgent need for quality control of cell-free extracellular matrix'scaffolds and their role in regenerative medicine. J Biomed Mater Res B Appl Biomater 106:909-923. https://doi.org/10.1002/jbm.b.33865

Kim BS, Choi JS, Kim JD, Choi YC, Cho YW (2012) Recellularization of decellularized human adipose-tissue-derived extracellular matrix sheets with other human cell types. Cell Tissue Res 348:559-567. https://doi.org/10.1007/s00441-012-1391-y

Laronda MM, Jakus AE, Whelan KA, Wertheim JA, Shah RN, Woodruff TK (2015) Initiation of puberty in mice following decellularized ovary transplant. Biomaterials 50:20-29. https://doi.org/10. 1016/j.biomaterials.2015.01.051

Lim NSJ, Hamed Z, Yeow CH, Chan C, Huang Z (2011) Early detection of biomolecular changes in disrupted porcine cartilage using polarized Raman spectroscopy. J Biomed Optics 16(1):017003. https://doi.org/10.1117/1.3528006

Lim LJ, Ling LH, Neo YP, Chung AYF, Goh BKP, Chow PKH, Chan CY, Cheow PC, Lee SY, Lim TKH, Chong SS, Ooi LLPJ, Lee CG (2019) Human amnion-derived mesenchymal stem cell (hADMSC) transplantation improves ovarian function in rats with premature ovarian insufficiency (POI) at least partly through a paracrine mechanism. Stem Cell Res Ther 10:1-18. https://doi. org/10.1186/s13287-019-1136-X

Liu WY, Lin SG, Zhuo RY, Xie YY, Pan W, Lin XF, Shen FX (2017) Xenogeneic decellularized scaffold: a novel platform for ovary regeneration. Tissue Eng Part C Methods 23:61-71. https://doi. org/10.1089/ten.TEC.2016.0410

Lv XG, Feng C, Fu Q, Xie H, Wang Y, Huang JW, Xie MK, Atala A, Xu YM, Zhao WX (2016) Comparative study of different seeding methods based on a multilayer SIS scaffold: Which is the optimal procedure for urethral tissue engineering? J Biomed Mater Res B Appl Biomater 104:1098-1108. https://doi.org/10.1002/jbm.b. 33460

Mirzaeian L, Eivazkhani F, Hezavehei M, Moini A, Esfandiari F, Valojerdi MR, Fathi R (2020) Optimizing the cell seeding protocol to human decellularized ovarian scaffold: application of dynamic system for bio-engineering. Cell J 22(2):227-235. https://doi.org/ 10.22074/cellj.2020.6604

Movasaghi Z, Rehman S, Rehman IU (2007) Raman spectroscopy of biological tissues. Appl Spectrosc Rev 42:493-541. https://doi. org/10.1080/05704920701551530

Na J, Kim GJ (2020) Recent trends in stem cell therapy for premature ovarian insufficiency and its therapeutic potential: a review. J Ovarian Res 13:1-10. https://doi.org/10.1186/ s13048-020-00671-2

Nguyen T, Gobinet C, Feru J, Brassart-Pasco S, Manfait M, Piot O (2012) Characterization of type I and IV collagens by Raman microspectroscopy: Identification of spectral markers of the dermo-epidermal junction. Spectrosc an Int J 27:421-427. https:// doi.org/10.1155/2012/686183
Nikniaz H, Zandieh Z, Nouri M, Daei-Farshbaf N, Aflatoonian R, Gholipourmalekabadi M, Jameie SB (2021) Comparing various protocols of human and bovine ovarian tissue decellularization to prepare extracellular matrix-alginate scaffold for better follicle development in vitro. BMC Biotechnol 21:1-8. https://doi.org/10. 1186/s12896-020-00658-3

Pennarossa G, Ghiringhelli M, Gandolfi F, Brevini TAL (2020) Wholeovary decellularization generates an effective 3D bioscaffold for ovarian bioengineering. J Assist Reprod Genet 37:1329-1339. https://doi.org/10.1007/s10815-020-01784-9

Pomin VH, Mulloy B (2018) Glycosaminoglycans and proteoglycans. Pharmaceuticals (basel) 11(1):27. https://doi.org/10.3390/ph110 10027

Pors SE, Ramløse M, Nikiforov D, Lundsgaard K, Cheng J, Andersen CY, Kristensen SG (2019) Initial steps in reconstruction of the human ovary: survival of pre-antral stage follicles in a decellularized human ovarian scaffold. Hum Reprod 34:1523-1535. https:// doi.org/10.1093/humrep/dez077

Porzionato A, Stocco E, Barbon S, Grandi F, Macchi V, De Caro R (2018) Tissue-engineered grafts from human decellularized extracellular matrices: a systematic review and future perspectives. Int J Mol Sci 19:4117. https://doi.org/10.3390/ijms19124117

Rajabi Z, Yazdekhasti H, Noori Mugahi SMH, Abbasi M, Kazemnejad S, Shirazi A, Majidi M, Zarnani AH (2018) Mouse preantral follicle growth in 3D co-culture system using human menstrual blood mesenchymal stem cell. Reprod Biol 18(1):122-131. https://doi. org/10.1016/j.repbio.2018.02.001

Simsa R, Padma AM, Heher P, Hellström M, Teuschl A, Jenndahl L, Bergh N, Fogelstrand P (2018) Systematic in vitro comparison of decellularization protocols for blood vessels. PLoS ONE. https:// doi.org/10.1371/journal.pone.0209269

White DM, Carruthers CA, Warner HJ, Kramer CR, Reing JE, Zhang L, D'Amore A, Badylak SF (2014) The effect of detergents on the basement membrane complex of a biologic scaffold material. Acta Biomater 10:183-193. https://doi.org/10.1016/j.actbio. 2013.09.006

White LJ, Taylor AJ, Faulk DM, Keane TJ, Saldin LT, Reing JE, Swinehart IT, Turner NJ, Ratner BD, Badylak SF (2017) The impact of detergents on the tissue decellularization process: a ToF-SIMS study. Acta Biomater 50:207-219. https://doi.org/10. 1016/j.actbio.2016.12.033

Xia X, Wang T, Yin T, Yan L, Yan J, Lu C, Zhao L, Li M, Zhang Y, Jin H, Zhu X, Liu P, Li R, Qiao J (2015) Mesenchymal stem cells facilitate in vitro development of human preantral follicle. Reprod Sci 22(11):1367-1376. https://doi.org/10.1177/19337 19115578922

Publisher's Note Springer Nature remains neutral with regard to jurisdictional claims in published maps and institutional affiliations. 